OPEN ACCESS

Edited by:

Mariele Gatto,

University of Gothenburg, Sweden

Reviewed by:

Manuel Alfredo Podestà,

University of Milan, Italy

Seerapani Gopaluni,

University of Cambridge,

United Kingdom

*Correspondence:

Paolo Cravedi

paolo.cravedi@mssm.edu

${ }^{\text {t}}$ These authors have contributed equally to this work

${ }^{\ddagger}$ These authors share senior authorship

Specialty section: This article was submitted to Autoimmune and

Autoinflammatory Disorders, a section of the journal

Frontiers in Immunology

Received: 16 June 2021 Accepted: 01 September 2021 Published: 21 September 2021

Citation:

Fribourg M, Cioni M, Ghiggeri G, Cantarelli C, Leventhal JS,

Budge K, Bin S, Riella LV, Colucci M, Vivarelli M, Angeletti A,

Perin $L$ and Cravedi $P$ (2021) CyTOF-Enabled Analysis Identifies Class-Switched B Cells as the Main Lymphocyte Subset Associated With Disease Relapse in Children With Idiopathic Nephrotic Syndrome.

Front. Immunol. 12:726428 doi: 10.3389/fimmu.2021.726428

\section{CyTOF-Enabled Analysis Identifies Class-Switched B Cells as the Main Lymphocyte Subset Associated With Disease Relapse in Children With Idiopathic Nephrotic Syndrome}

Miguel Fribourg ${ }^{1 \dagger}$, Michela Cioni ${ }^{2 \dagger}$, GianMarco Ghiggeri ${ }^{2}$, Chiara Cantarelli ${ }^{1,3}$, Jeremy S. Leventhal ${ }^{4}$, Kelly Budge ${ }^{1}$, Sofia Bin ${ }^{1}$, Leonardo V. Riella ${ }^{5}$, Manuela Colucci ${ }^{6}$, Marina Vivarelli ${ }^{7}$, Andrea Angeletti ${ }^{2}$, Laura Perin ${ }^{8 \neq}$ and Paolo Cravedi ${ }^{1 *}$

\footnotetext{
${ }^{1}$ Department of Medicine, Icahn School of Medicine at Mount Sinai, New York, NY, United States, ${ }^{2}$ Nephrology, Dialysis and Transplantation Unit, Istituto di Ricovero e Cura a Carattere Scientifico (IRCCS) Istituto Giannina Gaslini, Genova, Italy, ${ }^{3}$ Dipartimento di Medicina e Chirurgia Università di Parma, Unitá Operativa (UO) Nefrologia, Azienda OspedalieraUniversitaria Parma, Parma, Italy, ${ }^{4}$ Division of Nephrology, White Plains Hospital, White Plains, NY, United States, ${ }^{5}$ Center for Transplantation Sciences, Division of Nephrology, Massachusetts General Hospital, Harvard Medical School, Boston, MA, United States, ${ }^{6}$ Renal Diseases Research Unit, Genetics and Rare Diseases Research Area, Bambino Gesù Children's Hospital IRCCS, Rome, Italy, ${ }^{7}$ Division of Nephrology, Department of Pediatric Subspecialties, Bambino Gesù Children's Hospital IRCCS, Rome, Italy, ${ }^{8}$ Gabriel Organization for All Renal Research (GOFARR) Laboratory, Children's Hospital Los Angeles, Division of Urology, Saban Research Institute, University of Southern California, Los Angeles, CA, United States
}

B cell depleting therapies permit immunosuppressive drug withdrawal and maintain remission in patients with frequently relapsing nephrotic syndrome (FRNS) or steroiddependent nephrotic syndrome (SDNS), but lack of biomarkers for treatment failure. Postdepletion immune cell reconstitution may identify relapsing patients, but previous characterizations suffered from methodological limitations of flow cytometry. Time-offlight mass cytometry (CyTOF) is a comprehensive analytic modality that simultaneously quantifies over 40 cellular markers. Herein, we report CyTOF-enabled immune cell comparisons over a 12-month period from 30 children with SDNS receiving B cell depleting therapy who either relapsed $(n=17)$ or remained stable $(n=13)$. Anti-CD20 treatment depleted all B cells subsets and CD20 depleting agent choice (rituximab vs ofatumumab) did not affect B cell subset recovery. Despite equal total numbers of B cells, 5 subsets of B cells were significantly higher in relapsing individuals; all identified subsets of $B$ cells were class-switched. $T$ cell subsets (including $T$ follicular helper cells and regulatory $T$ cells) and other major immune compartments were largely unaffected by $B$ cell depletion, and similar between relapsing and stable children. In conclusion, CyTOF analysis of immune cells from anti-CD20 antibody treated patients identifies classswitched B cells as the main subset whose expansion associates with disease relapse. Our findings set the basis for future studies exploring how identified subsets can be used to monitor treatment response and improve our understanding of the pathogenesis of the disease.

Keywords: nephrotic syndrome, B cell, T cell, predictor, relapse, immune phenotype 


\section{INTRODUCTION}

Pathogenesis of idiopathic nephrotic syndrome (INS), the most frequent pediatric glomerular disease (1), remains poorly understood. Familial forms of INS are characterized by genetic abnormalities $(2,3)$, whereas non-genetic INS forms are hypothetically immune-mediated, possibly via unknown circulating permeability factors (4). The prevailing hypothesis, enshrined by a classic 1974 Shalhoub article in The Lancet, posits INS as a T cell disorder (5). Accordingly, first-line treatment for INS are corticosteroids with a complete remission rate of about $80 \%$. However, after initial responses, $40 \%-50 \%$ of patients can experience frequent relapsing-remitting episodes and become steroid-dependent or, eventually, steroid-resistant (6-8).

Pathogenic contribution from B cells was suggested in 2006, when Pescovitz et al. described the case of a 7-year-old boy with post-transplant focal segmental glomerulosclerosis recurrence [FSGS, thought to represent an evolution of minimal change disease, MCD (9)] who underwent remission after he received B-cell depletion to treat post-transplant lymphoproliferative disease (PTLD) (10). Subsequently, numerous case reports and clinical trials documented efficacy of B cell depleting therapies in inducing/maintaining long-term remission (11-14). Some reports document temporal correlation between $B$ cell reconstitution and relapse $(15,16)$, while other patients remain in remission despite B cell recovery $(17,18)$. This formed the basis for our studies testing the hypothesis that differential immune cell frequencies during B cell recovery underlie differences in relapsing versus non-relapsing patients after B cell depletion.

Past analyses of B cell depleted patients relied on flow cytometry, which limited the scope of immune compartment analysis. We hypothesized that comprehensive and longitudinal peripheral immune cell analysis of reconstituted $\mathrm{B}$ and $\mathrm{T}$ cell subpopulations would confirm or identify new associations to predict/identify disease relapse post B cell depletion therapy. To address challenges of previous studies, we used time-of-flight mass cytometry (CyTOF) which utilizes heavy metal labeled antibodies, instead of fluorophores, to create immunophenotyping panels that are quantified by mass spectrometry. We analyzed and compared PBMC samples from steroid-dependent nephrotic syndrome (SDNS) patients who relapsed to those that did not after initially responding to $\mathrm{B}$ cell depletion (Figure 1A). CyTOF allows deconvolution analysis of over 40 distinct antibody markers to comprehensively characterize immune phenotypes. Using unbiased clustering, we assessed changes and tested for relationships with disease activities in (i) B cells subsets, ii) $\mathrm{CD} 4^{+}$ and $\mathrm{CD}^{+} \mathrm{T}$ cell subsets, and iii) the major immune compartments.

\section{METHODS}

\section{Subjects and Sample Collection}

We performed CyTOF analyses on frozen PBMCs serially collected from patients with SDNS maintained in remission with oral steroids and calcineurin inhibitors (CNI). SDNS was defined by two consecutive relapses during corticosteroid therapy tapering or within 14 days of steroid withdrawal that responded to the association of prednisone with cyclosporine or tacrolimus.

All the patients were in complete remission at enrollment and received a single dose of either ofatumumab (OFA, $1500 \mathrm{mg} /$ $1.73 \mathrm{~m}^{2}$ ) or rituximab (RTX, $375 \mathrm{mg} / \mathrm{m}^{2}$ ) infusion, as part of a randomized trial (NCT02394119 and Eudract.ema.europe.eu: 2015-000624-28) (19). After infusion, steroids were progressively tapered off until complete withdrawal, which happened within 3 weeks. At one week after complete steroid withdrawal, CNI were withdrawn within 3 weeks. For the present study, we included 17 patients who underwent a relapse of NS after full immunosuppression withdrawal and 13 controls who did not undergo relapse over the same follow-up period. PBMC were collected before OFA or RTX infusion (T0), during remission after immunosuppression withdrawal (T1), and at the time of relapse or at a similar time-point after OFA or RTX therapy in non-relapsing patients (T2). At T2, relapsing patients had already received steroid therapy to promote remission.

Complete remission was defined by urinary protein over creatinine ratio (uPCR) $<200 \mathrm{mg} / \mathrm{g}(<20 \mathrm{mg} / \mathrm{mmol})$ or $1+$ protein on urine stick for 3 consecutive days (20). Partial remission was defined by proteinuria reduction of $50 \%$ or greater from the presenting value and absolute uPCR between 200 and $2000 \mathrm{mg} / \mathrm{g}(20-200 \mathrm{mg} / \mathrm{mmol})$. NS relapse was defined as $\mathrm{uPCR} \geq 2000 \mathrm{mg} / \mathrm{g}$ ( $\geq 200 \mathrm{mg} / \mathrm{mmol}$ ) or $\geq 3+$ protein on urine dipstick for 3 consecutive days.

The study was approved by the Institutional Review Board at the participating centers.

Study coordinator illustrated the project, delivered the information material and collected written informed consent from parents and child assent for treatment and collection of samples. Participants or their families could withdraw the consent at any time during the study.

\section{CyTOF Sample Preparation}

To limit batch effect, we barcoded samples collected from the same subjects at 3 different times with anti-CD45 antibodies conjugated to unique metal isotopes before pooling the samples together. CyTOF sample preparation was conducted as previously reported by others (21). Antibodies were either purchased preconjugated from Fluidigm (formerly DVS Sciences, San Francisco, CA) or purchased purified and conjugated in-house using MaxPar X8 Polymer Kits (Fluidigm, San Francisco, CA) according to the manufacturer's instructions. Ninety samples (30 subjects, 3 timepoints) were processed in 3 separate batches barcoded using 3 barcoding antibodies and pooled together. All PBMCs were stained with a panel of 38 antibodies (37 for clustering, 1 for viability) (Supplementary Table 1).

\section{CyTOF Data Acquisition}

CyTOF data were acquired at Icahn School of Medicine at Mount Sinai as previously reported by others (21). Samples were acquired on a CyTOF2 (Fluidigm) equipped with a SuperSampler fluidics system (Victorian Airships) at a concentration of 1 million cells $/ \mathrm{ml}$ in deionized water containing a 1/20 dilution of EQ 4 Element 
A

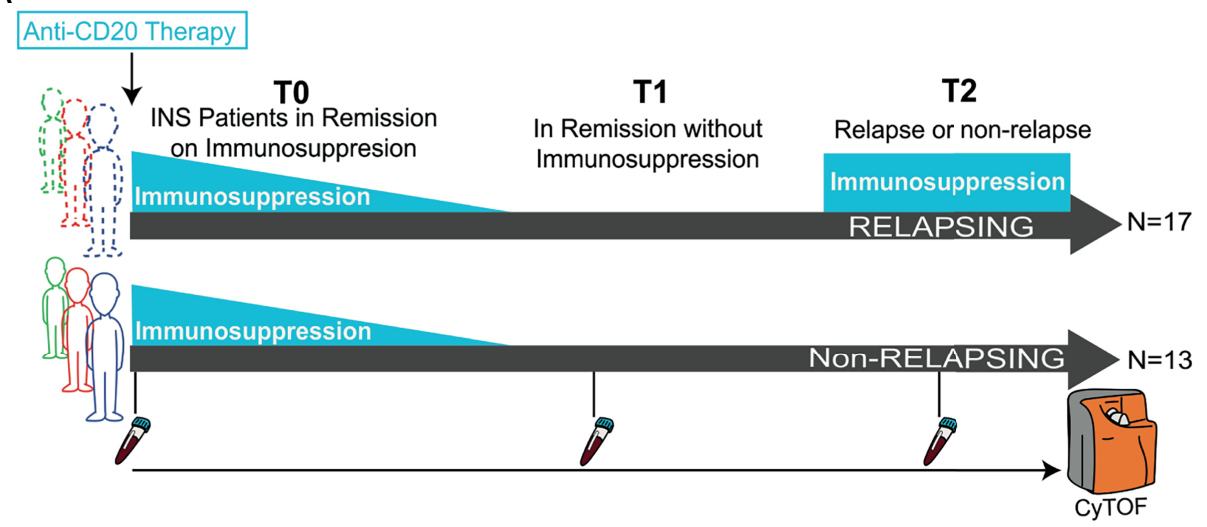

B

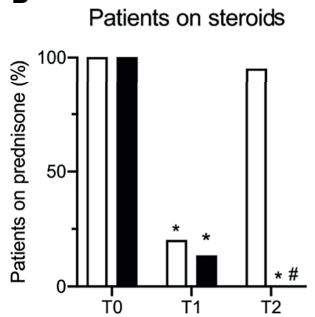

C

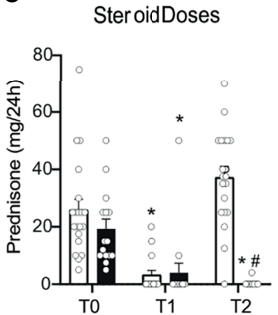

D

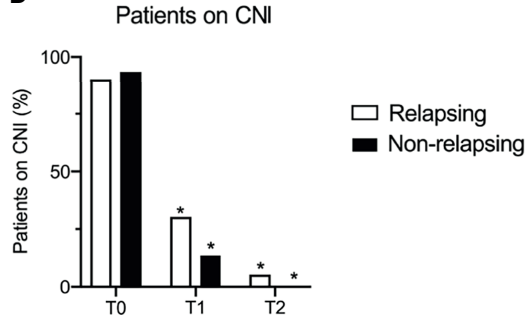

FIGURE 1 | Serial high-dimensional profiling of INS patients and concomitant immunosuppressive treatments. (A) Study design of thirty children with steroiddependent nephrotic syndrome in remission with steroids \pm calcineurin inhibitors who received either rituximab (RTX) or ofatumumab (OFA) and then underwent withdrawal of immunosuppression in 3 months. After withdrawal, 17 patients developed a relapse, while 13 stayed in remission. Blood was collected before RTX or OFA therapy (T0), after immunosuppressive withdrawal (while still in remission; T1), and at the time of relapse (or at the same time after B cell depleting therapy in patients in remission; T2). Cells were barcoded for patient and time, pooled, and stained with 38 antibodies conjugated to unique metal isotopes. Single-cell data acquired from time-of-flight mass cytometry (CyTOF) was clustered using Phenograph to identify cell clusters and how they evolved over time in each patient (see Methods). (B) Percentage of patients treated with prednisone and (C) average daily prednisone doses in relapsing and non-relapsing patients before anti-CD20 therapy (TO), in remission after immunosuppression withdrawal (T1), and at relapse (or at the same time point after anti-CD-20 therapy in non-relapsing patients; T2). (D) Percentage of patients treated with calcineurin inhibitors (CNI) at the same visits. $n=30$. ${ }^{*} p<0.05$ vs. T0. ${ }^{*} p<0.05$ vs. relapsing at the same visit. Bar plots depict mean \pm SEM.

Beads (Fluidigm) and at an event rate of $<500$ events/second. After acquisition, the data were normalized using bead-based normalization in the CyTOF software. Barcodes were demultiplexed using the Fluidigm debarcoding software. The data were gated to exclude residual normalization beads, debris, dead cells, and doublets, leaving live $\mathrm{CD} 45^{+}$events for subsequent clustering and high-dimensional analyses.

\section{CyTOF Data Analyses}

We first clustered cells using the PhenoGraph algorithm (21) and we then curated the 20 metaclusters obtained. The frequencies for each common population were obtained by summation of the frequencies in each metacluster and subsequently debarcoded to obtain frequencies for each timepoint and patient. To minimize variability in measurement, our analysis strategy was structured as follows:

i. Application of FlowSOM to computationally pooled samples: we pooled in silico all labeled cells from all timepoints together for each patient to analyze the major immune compartments (10,000 cells per timepoint for a total of 30,000 cells per patient), we applied FlowSOM, and then demultiplexed them. This allowed mapping of the same subsets in all the samples.

ii. Equal contribution of the samples: to avoid bias in FlowSOM for the subsets present in the samples with a greater number of $\mathrm{CD}^{+}$or $\mathrm{CD}^{+}$we maintained an equal contribution in the number of cells from every sample determined by the sample with the lowest number of $\mathrm{CD}^{+}$or $\mathrm{CD}^{+} \mathrm{T}$ cells.

iii. Reiteration: to increase power of the analyses for the cell subsets with low number of events, we reiterated the entirety of the sampling process and FlowSOM clustering up to 3 times to achieve robustness in the results.

Despite the level of stringency imposed by the repeated sampling and clustering process, we observed little dispersion in the results indicating that our findings were robust.

We did not observe significant differences in the average and $\mathrm{SD}$ of the signal for each marker nor in the frequencies of the major immune compartments across batches. 
The number of $\mathrm{CD}_{4} 5^{+}$cells $/ \mathrm{mm}^{3}$ was derived from measurements of the number of lymphocytes (T, B and NK cells) in each patient based on the frequencies of those major immune compartments.

\section{Cell Number Counts}

Absolute cell number counts were obtained from total lymphocyte counts available from $\mathrm{CBCs}$ performed on these samples multiplied by the frequencies derived from the CyTOF analysis.

\section{Statistics}

Statistical significance was determined by GraphPad Prism or R. Statistical tests used are reported in the figure legends. To establish all comparisons within relapsing and non-relapsing at different timepoints we performed a two-way ANOVA test, without assuming sphericity (Geisser-Green house correction) correcting for multiple comparisons by controlling the False Discovery Rate using the two-state step-up method of Benjamini and Yekutieli. Differences are considered significant at $\mathrm{p} \leq 0.05$.

\section{RESULTS}

\section{Baseline Patients' Characteristics}

We analyzed serial peripheral blood samples from 30 children with SDNS: baseline characteristics of included patients are shown in Table 1. At time of anti-CD20 therapy (before RTX or OFA; given at T0), all but one patient were receiving steroids and calcineurin inhibitors (Figures 1B-D). After receiving antiCD20 therapy, patients underwent immunosuppressive withdrawal, and at T1 [after an overall median of 4.1 months (IQR 3.0 - 7.1); 3.0 (3.0-7.3) and 3.0 (3.0-7.0) months for relapsing and non-relapsing patients, respectively], all patients were still in complete remission with reduced or no immunosuppression (Figures 1B-D). During a median followup period of 7.2 months (IQR 6.0 - 11.8) (T2), NS relapse occurred in 17 patients [T2: 6.5 months (5.0-7.8)] who restarted steroids, while remission persisted in 13 [T2: 8.0 months (6.09.0)]. At the same visit (T2), non-relapsing patients were in remission with no immunosuppression (Figures 1B-D). There was no difference in relapse rates between RTX and OFA treated patients.

\section{Changes in the Major Circulating Immune Compartments After B-Cell Depletion}

We quantified and compared major immune compartment kinetics using unbiased clustering (Phenograph Clustering Algorithm (22), see Methods) with 12 markers and viSNE to visualize high-dimensional data in two dimensions while preserving single-cell resolution (23) (Figure 2A). B cell frequencies were significantly reduced after anti-CD20 treatment (OFA and RTX) and returned toward baseline values at T2 (Figures 2B, C). Frequencies of other major immune compartments, including macrophages, dendritic cells (DCs), plasmacytoid dendritic cells (pDCs), monocytes, NK cells, $\mathrm{CD} 4^{+} \mathrm{T}$ cells, $\mathrm{CD} 8^{+} \mathrm{T}$ cells and $\mathrm{CD} 4^{-} \mathrm{CD} 8^{-} \mathrm{T}$ cells were not significantly affected by $\mathrm{B}$ cell depletion (visits $\mathrm{T} 0$ and $\mathrm{T} 1$; Figures 2B, C). At T2, relapsing patients had significantly decreased $\mathrm{NK}$ and $\mathrm{pDCs}$ and increased monocytes and $\mathrm{CD} 8^{+}$ $\mathrm{T}$ cell frequencies compared to non-relapsing patients (Figures 2B, C).

TABLE 1 | Baseline characteristics of study participants.

\begin{tabular}{|c|c|c|c|c|}
\hline & Total $(n=30)$ & Relapsing $(n=17)$ & Non-relapsing $(n=13)$ & P-value \\
\hline \multicolumn{5}{|l|}{ Demographics } \\
\hline Age (yrs) & $11.6 \pm 6.9$ & $11.1 \pm 6.7$ & $12.3 \pm 7.4$ & 0.65 \\
\hline Female & $6(20)$ & $2(12)$ & $4(31)$ & \\
\hline Male & $24(80)$ & $15(88)$ & $9(69)$ & \\
\hline Treatment & & & & 0.29 \\
\hline Rituximab n (\%) & $15(50)$ & $10(59)$ & $5(38)$ & \\
\hline Number of prior relapses, $n$ & $1.5(1-10)$ & $2(1-10)$ & $1(1-6)$ & 0.52 \\
\hline \multicolumn{5}{|c|}{ Immunosuppressive drugs at enrollment (TO), $n$ (\%) } \\
\hline Steroids & $30(100)$ & $17(100)$ & $13(100)$ & 1.0 \\
\hline Tac & $16(53)$ & $9(53)$ & $7(58)$ & 0.96 \\
\hline CsA & $13(43)$ & $8(47)$ & $5(38)$ & 0.63 \\
\hline \multicolumn{5}{|l|}{ Labs } \\
\hline $\lg A(m g / d L)$ & $658 \pm 231$ & $638 \pm 243$ & $685 \pm 221$ & 0.59 \\
\hline $\lg M(g / d L)$ & $166 \pm 109$ & $162 \pm 127$ & $171 \pm 84$ & 0.82 \\
\hline $\lg G(\mathrm{mg} / \mathrm{dL})$ & $144 \pm 83$ & $150 \pm 99$ & $134 \pm 60$ & 0.60 \\
\hline Proteinuria (mg/24 h) & $99 \pm 83$ & $116 \pm 104$ & $78 \pm 36$ & 0.18 \\
\hline
\end{tabular}

Data are mean $\pm S D$ number (\%), or median (range). $p$-value compares the two treatment groups in a two-tailed $t$-test of heteroscedastic variance or chi squared. Tac, tacrolimus: CsA, cyclosporine. 
A

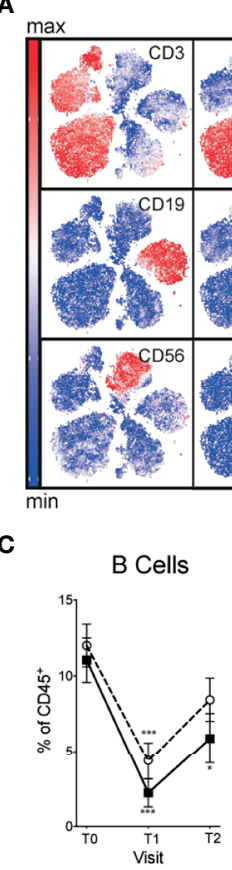

$\max$
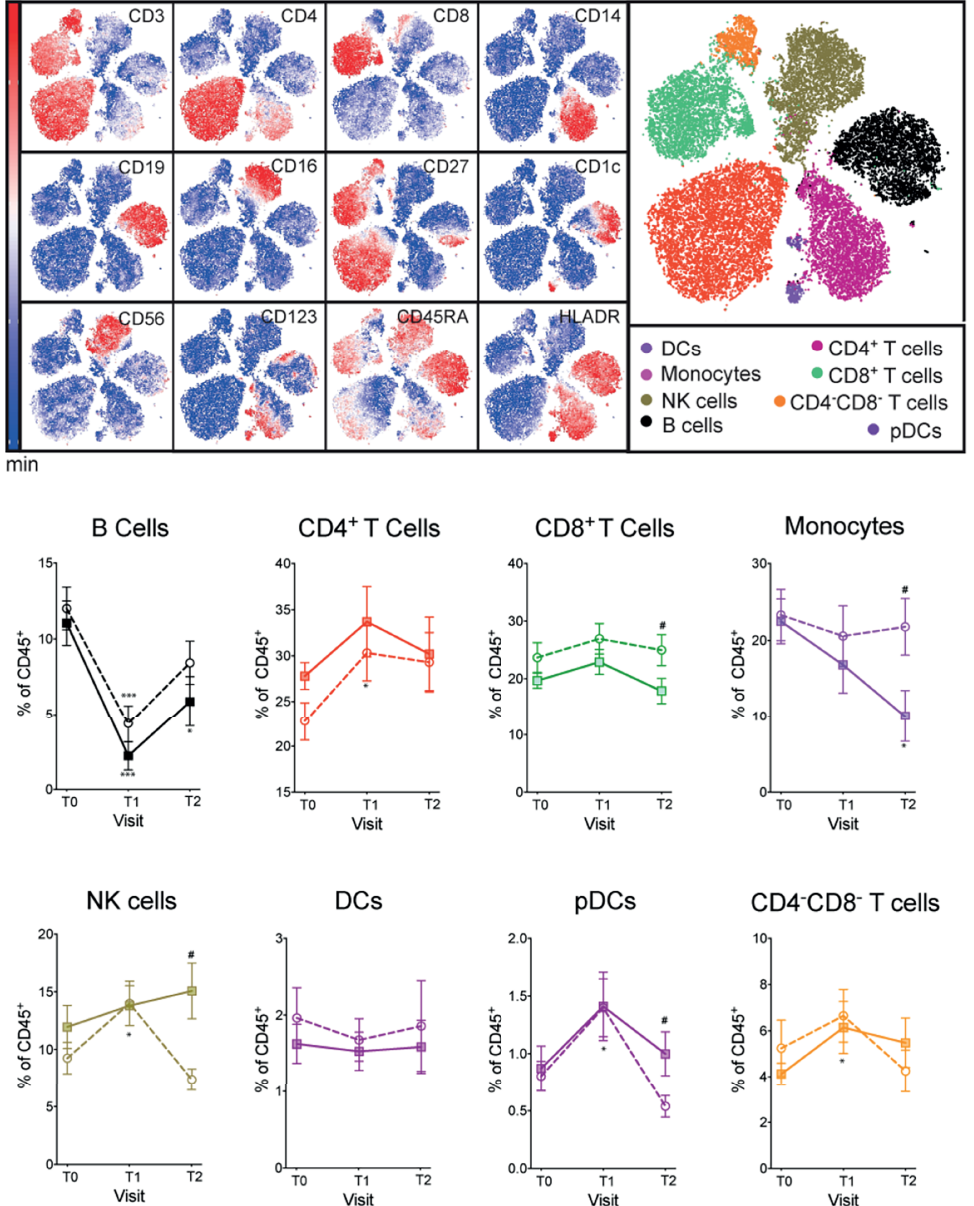

$\mathrm{CD} 4^{+} \mathrm{T}$ Cells

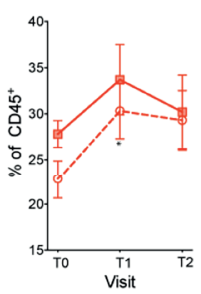

DCs

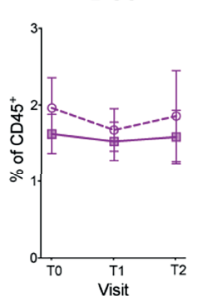

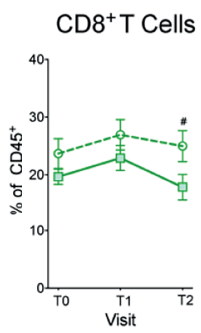

pDCs

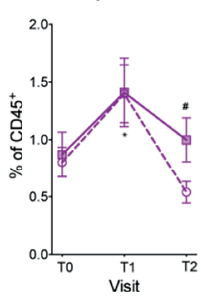

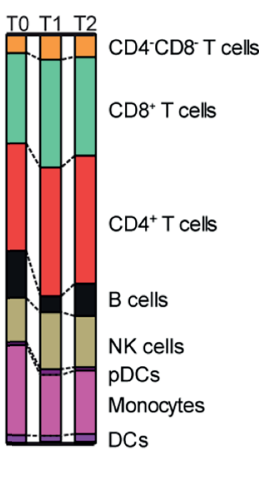

FIGURE 2 | Frequencies of major immune compartments in INS patients receiving OFA or RTX therapy. (A) viSNE analysis of peripheral blood mononuclear cells (PBMC) from a representative patient including 3 time points (during immunosuppressive treatment, after immunosuppressive treatment withdrawal and at the time of relapse) colored by the relative expression of CyTOF markers to designate major immune clusters [populations defined in (B)]. (C) Percentages of major immune compartments once demultiplexed and based on the summation of Phenograph clusters before (T0) and serially after (T1 and T2) anti-CD20 therapy. Comparisons between relapsing and non-relapsing at the same timepoint ${ }^{*} p<0.05$. Comparisons between different timepoints ${ }^{*} p<0.05,{ }^{* * *} p<0.001$. Two-way ANOVA corrected for multiple comparisons. Data points depict mean \pm SEM.

\section{Proportion of Switched B Cell Subsets Is Higher in Relapsing Patients}

Magnitude of $\mathrm{B}$ cells $\left(\mathrm{CD} 19^{+}\right)$decrease was similar between relapsing and non-relapsing patients (Figure 2C). Nadir B cell percentage in OFA-treated patients was significantly lower than in RXT-treated ones, but there was no significant difference between OFA and RTX in post-treatment B cell percentages or absolute numbers (Supplementary Figures 1A, B). We next compared kinetics and makeup of B cell subsets between relapsing and non-relapsing patients by performing a second level of unbiased clustering on B cells using 8 subset markers (CD127, CD21, IgM, IgD, CD27, CD95, CD38, CD25). B cells from all patients and all visits were pooled together, and clustered using B cell specific markers into subsets based on relative expression defining markers. Subsets were then demultiplexed to extract the subpopulation frequencies over time. We explored the different clusters using a heatmap displaying the relative expression of each marker per cluster and grouped them based on similarity (Figure 3A). Within the Bcell compartment we identified 10 distinct B-cell subpopulations, including $\mathrm{B}$ cells with a naïve $\left(\mathrm{IgD}^{+} \mathrm{CD} 27^{-}\right)(24)$, regulatory $\left(\mathrm{CD} 25^{\text {hi }}\right)(25,26)$, antibody secreting $\left(\mathrm{IgD}^{-}, \mathrm{CD} 27^{+}, \mathrm{CD} 38^{+}\right)(24)$, and memory phenotype $\left(\mathrm{IgD}^{+} \mathrm{CD} 27^{+} \mathrm{CD} 38^{-}\right)(24)$. Frequencies of transitional $\mathrm{B}$ cells, $\mathrm{B}$ regulatory cells $\left(\mathrm{B}_{\mathrm{REG}}\right)$, and class-switched memory (CSM) resting B cells significantly increased after therapy (Supplementary Figure 2) despite global decreases in absolute numbers (Figure 3B). While we did not observe differences in single subset frequencies between the two groups at analyzed timepoints (Supplementary Figure 2), we found that frequencies of switched $\mathrm{B}$ cell subsets altogether $\left(\mathrm{B}_{\mathrm{REG}}\right.$, CSM resting, CSM 


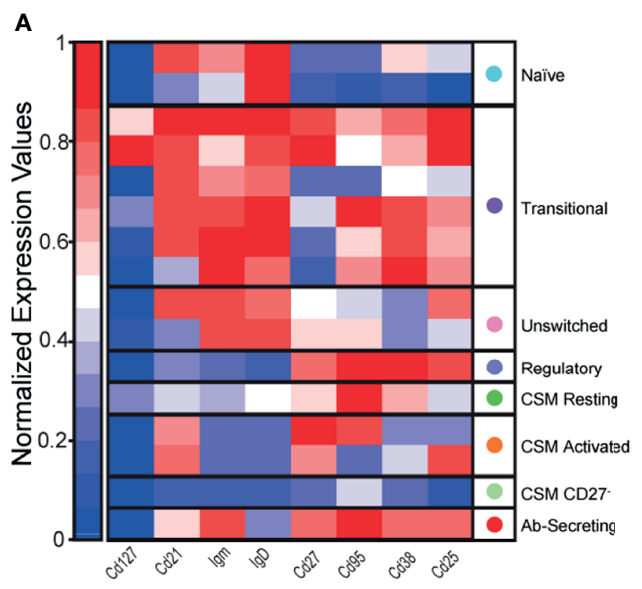

B
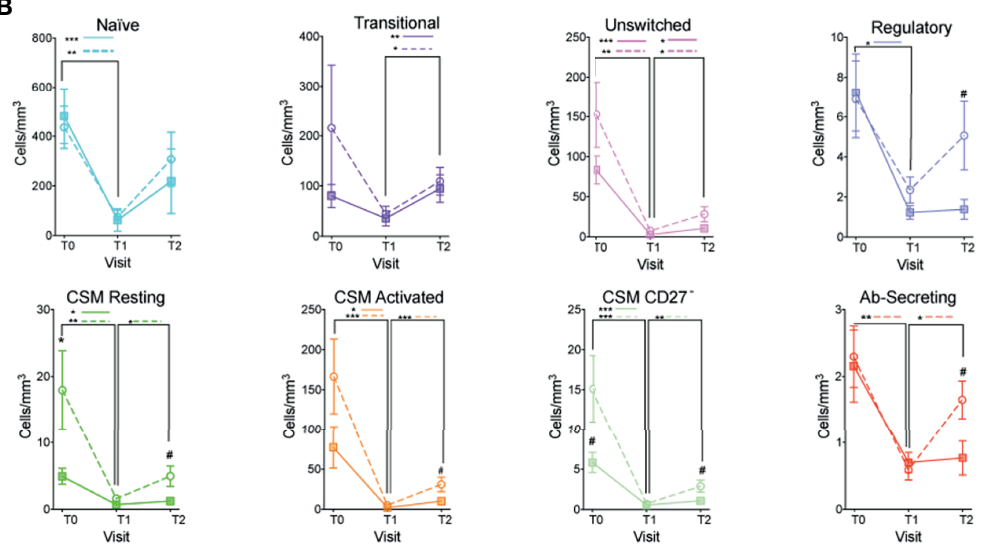

$\ominus$ Relapsing $\exists$ Non-relapsing

FIGURE 3 | Changes in B cell subsets after anti-CD20 Ab therapy. (A) Heatmap of CD19+ immune cells colored and labeled by Phenograph cluster for all subjects and time points combined (see Methods). Rows represent different clusters identified and columns the relative expression of each marker in that particular cluster (B) Absolute numbers of $\mathrm{CD}_{1} 9^{+} \mathrm{B}$ cell subsets once demultiplexed and based on the summation of Phenograph clusters before (T0) and serially after (T1 and T2) antiCD20 therapy. Comparisons between relapsing and non-relapsing at the same timepoint ${ }^{*} p<0.05$. Comparisons between different timepoints ${ }^{*} p<0.05$, ${ }^{* *} p<0.01$, ${ }^{* \star *} \mathrm{p}<0.001$. Two-way ANOVA corrected for multiple comparisons. Data points depict mean $\pm \mathrm{SEM}$.

activated, CSM CD27', and Ab-secreting B cells) were significantly higher in relapsing patients than in non-relapsing individuals, both at $\mathrm{T} 0$ and $\mathrm{T} 2$ (Figures $4 \mathrm{~A}, \mathbf{B}, \mathrm{p}<0.05)$. We also quantified composite absolute numbers of switched $\mathrm{B}$ cells and observed significantly higher numbers at $\mathrm{T} 2$ amongst relapsing patients (Figure 4C). At T1, there were no significant difference in switched B cells between individuals who fully withdrew immunosuppression and those who were on minimal residual immunosuppression (not shown).

\section{T Cell Subsets Are Not Different Between Relapsing and Non-Relapsing Patients}

We next quantified and compared $\mathrm{T}$ cell subset frequencies over time between relapsing and non-relapsing patients. Several investigators have observed differences in $\mathrm{T}$ cell subpopulations after $\mathrm{B}$ cell depleting therapies that implicate a role in treatment effect $(27,28)$. We performed a second level of unbiased clustering within $\mathrm{CD} 4^{+}$and $\mathrm{CD} 8^{+} \mathrm{T}$ cell compartments using
$18\left(\mathrm{CD}^{+}\right)$and $17\left(\mathrm{CD}^{+}\right)$subgroup markers, respectively $(\mathrm{PD}-1$, TIGIT, ICOS, CD57, TIM3, Foxp3 only for CD4+, 2b4, CTLA4, OX40, CCR6, CXCR5, CD45RO, CD95, CD127, CCR7, CD25, CXCR3, CD45RA) quantifying subpopulation differences between study groups (Supplementary Figure 3A and Supplementary Figure 4A).

At $\mathrm{T} 1$, absolute numbers of $\mathrm{CD} 4^{+} \mathrm{T}$ cells, as well as central and effector memory subgroups, were lower in relapsing patients, but their frequencies were not different (Supplementary Figures 3B, C). Percentages of regulatory $\mathrm{T}$ cells $\left(\mathrm{T}_{\mathrm{REG}}\right)-\mathrm{a} \mathrm{CD} 4^{+} \mathrm{T}$ cell subset whose reduction others associated with relapse risk $(29,30)$ - did not significantly differ between groups. $\mathrm{CD}^{+} \mathrm{T}$ cells with a $\mathrm{T}$-follicular helper-like $\left(\mathrm{T}_{\mathrm{FH}}\right)$ phenotype (see Supplementary Figure 3 clusters for markers), a population of crucial importance in antibody production, were also similar between groups.

Unfractionated $\mathrm{CD}^{+} \mathrm{T}$ cell absolute numbers over time were similar between relapsing and non-relapsing patients (Supplementary Figure 4C). At T2, absolute numbers (but not 
A

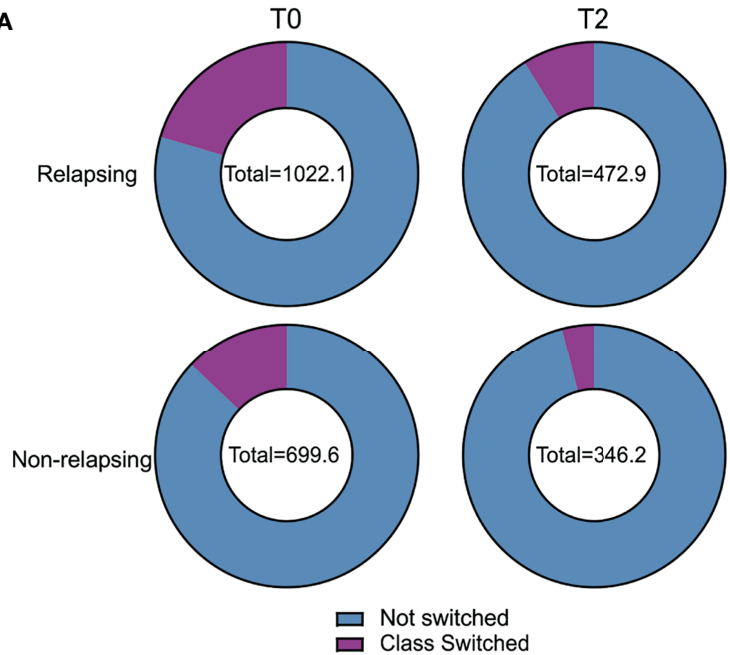

C

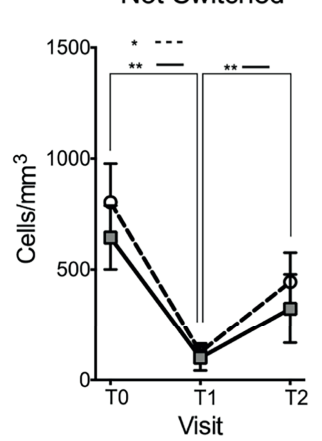

Class Switched

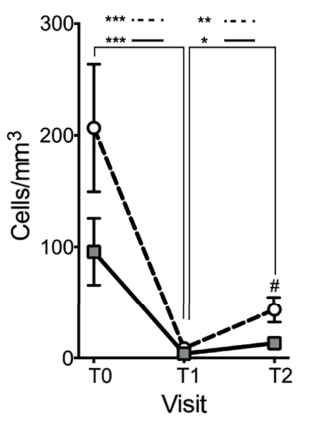

B

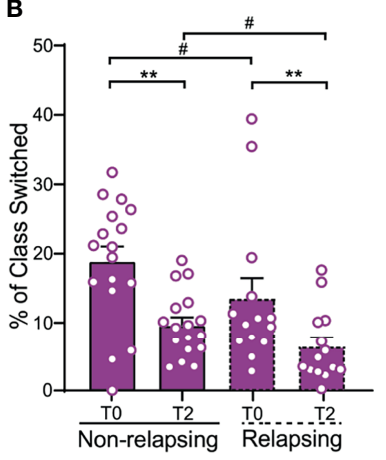

$\ominus$ Relapsing

* Non-relapsing

FIGURE 4 | Changes in not switched and class switched B cells after anti-CD2O Ab therapy. (A) Doughnut pie graph of the number of class switched B cells (total = average number of class switched and not-switched cells per sample) before anti-CD20 treatment (TO) and at relapse (or at the same time point after anti-CD-20 therapy in non-relapsing patients) (T2). (B) Bar graph illustrating the percentage of class switched B cells. (C) Changes in absolute numbers of not switched and class switched B cells in relapse and non-relapsing patients at T0, T1 and T2. Comparisons between the relapsing and non-relapsing groups at the same timepoint ${ }^{\#} p<0.05$. Comparisons between different timepoints ${ }^{*} \mathrm{p}<0.05,{ }^{* *} \mathrm{p}<0.01,{ }^{* * *} \mathrm{p}<0.001$. Two-way ANOVA corrected for multiple comparisons. Bar plots and data points depict mean \pm SEM.

percentages) of exhausted and effector memory (EM) $\mathrm{CD}^{+} \mathrm{T}$ cells were significantly higher in relapsing patients (Supplementary Figures 4B, C). At T1, there were no significant difference in $\mathrm{CD} 4+$ nor in $\mathrm{CD} 8+\mathrm{T}$ cells between individuals who fully withdrew immunosuppression and those who were on minimal residual immunosuppression (not shown).

\section{DISCUSSION}

Our work is the first CyTOF-enabled immune compartment survey of INS patients receiving B cell depleting therapies. Standard flow cytometry is limited in the number of markers that can be probed in a single experiment due to autofluorescence and spectral spillover associated with fluorophores. CyTOF utilizes metal isotopes that possess unique mass spectrometry signatures enabling the analysis of over 40 cellular markers at the same time. Furthermore, CyTOF reduces experimental variability as metal isotopes can be used to tag samples with barcodes, allowing simultaneous sample analysis. Even with limited samples, CyTOF increases the likelihood that our results are reproducible, making them more clinically relevant.

A previous study in INS patients showed that accelerated

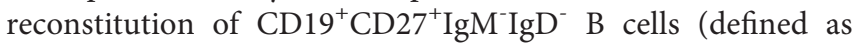
switched-memory) identifies patients at higher risk of disease recurrence (31). Our data corroborates this specific finding in memory cells and extends such results using a more comprehensive characterization of B cell clusters. B cell depletion strategies are widely used in treating other autoimmune diseases. The present data in INS patients add to several published studies showing that recovery of class-switched memory B cells heralds relapses of other autoimmune diseases such as myasthenia gravis, neuromyelitis optica, and rheumatoid arthritis $(32,33)$. Therefore, monitoring relevant $\mathrm{B}$ cell subsets could guide timing of repeat treatment with depleting therapies or use of alternative immunosuppression regimens. This provides advantages over 
current clinical management that relies on markers of end organ damage - proteinuria and serum creatinine.

Intriguingly, switched B cells were significantly higher in relapsing patients despite the fact that T2 samples were taken after the initiation of steroid therapy, which has been shown to reduce this cell population $(34,35)$, a phenomenon that has been observed prior in INS (35) and other autoimmune conditions (36).

Five subsets of switched B cells recovered early in patients with disease relapse. In addition to class-switched memory cells, IgD $\mathrm{CD} 27^{+} \mathrm{CD} 38^{+} \mathrm{CD} 95^{+} \mathrm{Ab}$-secreting cells represent the subset most strongly associated with disease recurrence (37). This subpopulation lacks IgD expression and is CD27 positive, signifying mature B cells (38), and additionally express CD38. CD38 is a highly conserved type II glycoprotein that possesses pleiotropic effects on B-cell function and maturation (39-41). CD38 induces apoptosis in early B cells but promotes survival in germinal center B cells (42). Antibody-secreting cells, made up of plasma cells and immature plasmablasts (43), express high levels of CD38, whereas memory B cells, also $\mathrm{IgD}^{-}$and $\mathrm{CD}^{+} 7^{+}$(44-46), lack CD38 expression $(47,48)$.

We also found that patients with disease relapse had a faster recovery of $\mathrm{CD}^{2} 5^{+} \mathrm{CD} 127^{-} \mathrm{IgD}^{-} \mathrm{IgM}^{-} \mathrm{B}$ cells, a phenotype compatible with $\mathrm{B}_{\text {REG }}$. These cells inhibit $\mathrm{T}$ cells through the release of IL-10, IL-35, and transforming growth factor $\beta$ (TGF$\beta$ ) and their importance is known for several autoimmune conditions (49-51). Originally identified as a transitional B cell subset, it is now known that $B_{\text {REG }}$ can acquire suppressive functions at different stages of development in response to environmental cues (52). Possibly, $\mathrm{B}_{\mathrm{REG}}$ expansion in relapsing patients reflects a compensatory mechanism to active antibody production, similar to expansion of regulatory $T$ cells $\left(T_{R E G}\right)$ in kidney transplant recipients with acute rejection (53). However, more studies are needed to determine whether their presence is directly or indirectly related to INS pathogenesis. We analyzed T cell subpopulations because antibody mediated diseases (e.g. membranous nephropathy) depend on cognate B cell-T cell interactions. Previous studies showed that RTX affects homing of $\mathrm{T}_{\mathrm{REG}}$ and $\mathrm{T}$ follicular helper cells $\left(\mathrm{T}_{\mathrm{FH}}\right)$ (54), possibly as a consequence of reduced interaction with B cells (55).

Most data on the efficacy of B cell depleting therapies in INS patients have been generated with rituximab, a chimeric anti-CD20 monoclonal antibody. Ofatumumab is a fully humanized anti-CD20 monoclonal antibody of last generation. OFA binds CD20 with more affinity, potentially leading to more efficient complement-dependent cytotoxicity $(56,57)$. In a small series, OFA-induced remission in children with SR-INS who did not respond to RTX (31). Our data confirm the higher peripheral B cell depleting efficacy of OFA compared to RTX. Despite this, kinetics of B cell reconstitution did not differ significantly between the two treatment arms suggesting that, at the doses used in our study, their effects on B cells in secondary lymphoid organs are similar. Because B cell reconstitution portended disease relapse, we hypothesized that differences in B cells subsets exist amongst patient groups.

B cell depleting agents have variable penetrance into secondary lymphoid structures. Relapse in patients with disproportionate persistence of antigen experienced B cells may represent preferential survival of autoreactive B cells.
Consistent with this hypothesis, our data showed trends for increased frequency of Ab-secreting B cells that first occurred when B cells were depleted (T1, Supplementary Figure 2).

Our data provide basis to pursue critical questions regarding antigen specificity of surviving/reconstituting cell populations. The present findings are also consistent with murine data showing that podocyte targeting antibodies are sufficient to change the glomerular filtration barrier and are the "permeability factor" in some patients with INS due to FSGS (58). Clinically, our findings suggest that combined B cell therapies (e.g. RTX + proteasomal inhibitor) could provide enhanced treatment efficacy by targeting all class-switched and Ab-secreting cells.

B cells, especially the ones expressing activation marker CD25, can act as antigen presenting cells to activate $\mathrm{T}$ cells (59). However, in contrast to B cell subsets, our comprehensive immune phenotypic analysis identified few significant differences between relapsing and non-relapsing patients in $\mathrm{CD}^{+}$and $\mathrm{CD} 8^{+}$ $\mathrm{T}$ cell clusters at T2. An exception to this were exhausted $\mathrm{CD} 8^{+} \mathrm{T}$ cells that were higher in relapsing patients. $T$ cell exhaustion arises from prolonged antigen exposure (60) and is observed in patients with chronic autoimmune diseases (61) or renal transplant recipients (62). Higher frequencies of exhausted $\mathrm{CD}^{+} \mathrm{T}$ cells in relapsing patients at $\mathrm{T} 2$ raises the intriguing hypothesis that $\mathrm{T}$ cell exhaustion is a marker of disease chronicity/activity, indicative of increased B cell activation.

The main immune cell compartments were largely comparable between relapsing and non-relapsing patients with the exception of monocytes and NK T cells which underwent reciprocal changes. Changes we observed are likely related to resumption of high-dose corticosteroids in relapsing patients (63). Absence of differences in major immune compartments is an important negative finding with respect to $\mathrm{B}$ cell depleting therapies and emphasizes how CyTOF powered analysis provides uniquely in-depth and broad analysis.

\section{Limitations}

Our study main limitation is the relatively limited sample size and the absence of prospective validation. Although the limitations associated with a small number of patients cannot be entirely overcome, CyTOF allowed comprehensive immune cell phenotyping with increased sensitivity for low-expressed markers. Therefore, we extracted a significant amount of information from a reduced number of samples. Additionally, we resampled and reanalyzed B-cell clusters 3 times to further ensure our findings were statistically robust and valid. Lastly, samples were run simultaneously, further decreasing variation due to technical issues.

Another intrinsic limitation of the study is the nonstandardized time for blood sampling, as the time of relapses could not be planned in advance. However, the frequent sampling allowed us an excellent matching in the sample timing between relapsing and non-relapsing patients.

Previous studies have shown that RTX may affect not only B-cell composition, but also their function (64). Lack of functional studies on reconstituted switched B cells prevents any definitive conclusion on the effect of these cells in relapsing and non-relapsing patients. Future studies will be required to address this relevant issue as well as antigen specificity of 
reconstituted populations in relapsed patients. Our work provides the most solid basis, to date, for interrogating classswitched B cells in these patients.

\section{CONCLUSIONS}

Overall, the present study demonstrates that 5 subsets of circulating switched B cells are preferentially increased in INS patients who relapsed after CD20-depleting therapies, suggesting a pathogenic link and potential for use as a biomarker. Our work provides focus and a strong rationale for future studies testing the hypothesis that monitoring the number and, potentially, function of switched B cells identifies patients at higher risk of relapse instead of using total B cells or clinical indicators, alone. Transcriptional and/or proteomic analyses of switched B cells in relapsing or non-relapsing patients may provide important mechanistic insights on INS pathogenesis.

\section{DATA AVAILABILITY STATEMENT}

The raw data supporting the conclusions of this article will be made available by the authors, without undue reservation.

\section{REFERENCES}

1. Eddy AA, Symons JM. Nephrotic Syndrome in Childhood. Lancet (2003) 362:629-39. doi: 10.1016/S0140-6736(03)14184-0

2. Gubler MC. Podocyte Differentiation and Hereditary Proteinuria/Nephrotic Syndromes. J Am Soc Nephrol (2003) 14(Suppl 1):S22-6. doi: 10.1097/ 01.asn.0000067648.75923.68

3. Lombel RM, Gipson DS, Hodson EM. Kidney Disease: Improving Global O: Treatment of Steroid-Sensitive Nephrotic Syndrome: New Guidelines From KDIGO. Pediatr Nephrol (2013) 28:415-26. doi: 10.1007/s00467-012-2310-x

4. Savin VJ, Sharma R, Sharma M, McCarthy ET, Swan SK, Ellis E, et al. Circulating Factor Associated With Increased Glomerular Permeability to Albumin in Recurrent Focal Segmental Glomerulosclerosis. N Engl J Med (1996) 334:878-83. doi: 10.1056/NEJM199604043341402

5. Shalhoub RJ. Pathogenesis of Lipoid Nephrosis: A Disorder of T-Cell Function. Lancet (1974) 2:556-60. doi: 10.1016/s0140-6736(74)91880-7

6. Teeninga N, Kist-van Holthe JE, van Rijswijk N, de Mos NI, Hop WC, Wetzels JF, et al. Extending Prednisolone Treatment Does Not Reduce Relapses in Childhood Nephrotic Syndrome. J Am Soc Nephrol (2013) 24:149-59. doi: 10.1681/ASN.2012070646

7. Tarshish P, Tobin JN, Bernstein J, Edelmann CMJr. Prognostic Significance of the Early Course of Minimal Change Nephrotic Syndrome: Report of the International Study of Kidney Disease in Children. J Am Soc Nephrol (1997) 8:769-76. doi: 10.1681/ASN.V85769

8. Nephrotic Syndrome in Children: A Randomized Trial Comparing Two Prednisone Regimens in Steroid-Responsive Patients Who Relapse Early. Report of the International Study of Kidney Disease in Children. J Pediatr (1979) 95:239-43.

9. Dumas de la Roque C, Prezelin-Reydit M, Vermorel A, Lepreux S, Deminiere C, Combe C, et al. Idiopathic Nephrotic Syndrome: Characteristics and Identification of Prognostic Factors. J Clin Med (2018) 7(9):265. doi: 10.3390/jcm7090265

10. Pescovitz MD, Greenbaum CJ, Krause-Steinrauf H, Becker DJ, Gitelman SE, Goland R, et al. Type 1 Diabetes TrialNet Anti CDSG: Rituximab, BLymphocyte Depletion, and Preservation of Beta-Cell Function. $N$ Engl J Med (2009) 361:2143-52. doi: 10.1056/NEJMoa0904452

11. Iijima K, Sako M, Nozu K, Mori R, Tuchida N, Kamei K, et al. Rituximab for Childhood-Onset Refractory Nephrotic Syndrome Study G: Rituximab for

\section{AUTHOR CONTRIBUTIONS}

PC, GG, MCo, and MF conceived and designed the study. MCi collected the samples. CC, JL, KB, and SB were involved in the preparation of samples for CyTOF analyses. MF performed all the statistical analyses. PC and MF critically interpreted the data and wrote the first draft of the manuscript together with LP. All authors contributed to the article and approved the submitted version.

\section{ACKNOWLEDGMENTS}

We thank the Human Immune Monitoring Center at the Icahn School of Medicine at Mount Sinai, New York, for their assistance with CyTOF studies. This work was supported from the GOFARR Foundation and the Schenkman Family.

\section{SUPPLEMENTARY MATERIAL}

The Supplementary Material for this article can be found online at: https://www.frontiersin.org/articles/10.3389/fimmu.2021. 726428/full\#supplementary-material

Childhood-Onset, Complicated, Frequently Relapsing Nephrotic Syndrome or Steroid-Dependent Nephrotic Syndrome: A Multicentre, Double-Blind, Randomised, Placebo-Controlled Trial. Lancet (2014) 384:1273-81. doi: 10.1016/S0140-6736(14)60541-9

12. Ravani P, Ponticelli A, Siciliano C, Fornoni A, Magnasco A, Sica F, et al. Rituximab Is a Safe and Effective Long-Term Treatment for Children With Steroid and Calcineurin Inhibitor-Dependent Idiopathic Nephrotic Syndrome. Kidney Int (2013) 84:1025-33. doi: 10.1038/ki.2013.211

13. Ravani P, Rossi R, Bonanni A, Quinn RR, Sica F, Bodria M, et al. Rituximab in Children With Steroid-Dependent Nephrotic Syndrome: A Multicenter, Open-Label, Noninferiority, Randomized Controlled Trial. J Am Soc Nephrol (2015) 26:2259-66. doi: 10.1681/ASN.2014080799

14. Ruggenenti P, Ruggiero B, Cravedi P, Vivarelli M, Massella L, Marasa M, et al. Rituximab in Nephrotic Syndrome of Steroid-Dependent or Frequently Relapsing Minimal Change Disease Or Focal Segmental Glomerulosclerosis Study G: Rituximab in Steroid-Dependent or Frequently Relapsing Idiopathic Nephrotic Syndrome. J Am Soc Nephrol (2014) 25:850-63. doi: 10.1681/ ASN.2013030251

15. Kamei K, Ito S, Nozu K, Fujinaga S, Nakayama M, Sako M, et al. Single Dose of Rituximab for Refractory Steroid-Dependent Nephrotic Syndrome in Children. Pediatr Nephrol (2009) 24:1321-8. doi: 10.1007/s00467-009-1191-0

16. Sellier-Leclerc AL, Macher MA, Loirat C, Guerin V, Watier H, Peuchmaur M, et al. Rituximab Efficiency in Children With Steroid-Dependent Nephrotic Syndrome. Pediatr Nephrol (2010) 25:1109-15. doi: 10.1007/s00467-0101465-6

17. Sellier-Leclerc AL, Baudouin V, Kwon T, Macher MA, Guerin V, Lapillonne $\mathrm{H}$, et al. Rituximab in Steroid-Dependent Idiopathic Nephrotic Syndrome in Childhood-Follow-Up After CD19 Recovery. Nephrol Dial Transplant (2012) 27:1083-9. doi: 10.1093/ndt/gfr405

18. Guitard J, Hebral AL, Fakhouri F, Joly D, Daugas E, Rivalan J, et al. Rituximab for Minimal-Change Nephrotic Syndrome in Adulthood: Predictive Factors for Response, Long-Term Outcomes and Tolerance. Nephrol Dial Transplant (2014) 29:2084-91. doi: 10.1093/ndt/gfu209

19. Ravani P, Bonanni A, Ghiggeri GM. Randomised Controlled Trial Comparing Ofatumumab to Rituximab in Children With Steroid-Dependent and Calcineurin Inhibitor-Dependent Idiopathic Nephrotic Syndrome: Study Protocol. BMJ Open (2017) 7:e013319. doi: 10.1136/bmjopen-2016-013319 
20. Kidney Disease. Improving Global Outcomes (KDIGO) Glomerulonephritis Work Group. KDIGO Clinical Practice Guideline for Glomerulonephritis. Kidney Inter (2012) Suppl 2:163-71. doi: 10.1038/kisup.2012.9

21. DiGiuseppe JA, Cardinali JL, Rezuke WN, Pe'er D. PhenoGraph and viSNE Facilitate the Identification of Abnormal T-Cell Populations in Routine Clinical Flow Cytometric Data. Cytometry B Clin Cytom (2018) 94:588-601. doi: $10.1002 /$ cyto.b. 21588

22. Levine JH, Simonds EF, Bendall SC, Davis KL, Amir el AD, Tadmor MD, et al. Data-Driven Phenotypic Dissection of AML Reveals Progenitor-Like Cells That Correlate With Prognosis. Cell (2015) 162:184-97. doi: 10.1016/ j.cell.2015.05.047

23. Lavin Y, Kobayashi S, Leader A, Amir ED, Elefant N, Bigenwald C, et al. Innate Immune Landscape in Early Lung Adenocarcinoma by Paired SingleCell Analyses. Cell (2017) 169:750-65.e717. doi: 10.1016/j.cell.2017.04.014

24. Luque S, Lucia M, Melilli E, Lefaucheur C, Crespo M, Loupy A, et al. Value of Monitoring Circulating Donor-Reactive Memory B Cells to Characterize Antibody-Mediated Rejection After Kidney Transplantation. Am J Transplant (2019) 19:368-80. doi: 10.1111/ajt.15055

25. Rosser EC, Mauri C. Regulatory B Cells: Origin, Phenotype, and Function. Immunity (2015) 42:607-12. doi: 10.1016/j.immuni.2015.04.005

26. van de Veen W, Stanic B, Yaman G, Wawrzyniak M, Sollner S, Akdis DG, et al. IgG4 Production Is Confined to Human IL-10-Producing Regulatory B Cells That Suppress Antigen-Specific Immune Responses. J Allergy Clin Immunol (2013) 131:1204-12. doi: 10.1016/j.jaci.2013.01.014

27. Marino J, Paster JT, Trowell A, Maxwell L, Briggs KH, Crosby Bertorini P, et al. B Cell Depletion With an Anti-CD20 Antibody Enhances Alloreactive Memory T Cell Responses After Transplantation. Am J Transplant (2016) 16:672-8. doi: 10.1111/ajt.13483

28. Sentis A, Diekmann F, Llobell A, de Moner N, Espinosa G, Yague J, et al. Kinetic Analysis of Changes in T- and B-Lymphocytes After Anti-CD20 Treatment in Renal Pathology. Immunobiology (2017) 222:620-30. doi: 10.1016/j.imbio.2016.11.011

29. Boumediene A, Vachin P, Sendeyo K, Oniszczuk J, Zhang SY, Henique C, et al. NEPHRUTIX: A Randomized, Double-Blind, Placebo vs RituximabControlled Trial Assessing T-Cell Subset Changes in Minimal Change Nephrotic Syndrome. J Autoimmun (2018) 88:91-102. doi: 10.1016/ j.jaut.2017.10.006

30. Tsuji S, Kimata T, Yamanouchi S, Kitao T, Kino J, Suruda C, et al. Regulatory T Cells and CTLA-4 in Idiopathic Nephrotic Syndrome. Pediatr Int (2017) 59:643-6. doi: 10.1111/ped.13255

31. Colucci M, Carsetti R, Cascioli S, Casiraghi F, Perna A, Rava L, et al. B Cell Reconstitution After Rituximab Treatment in Idiopathic Nephrotic Syndrome. J Am Soc Nephrol (2016) 27:1811-22. doi: 10.1681/ ASN.2015050523

32. Lebrun C, Cohen M, Rosenthal-Allieri MA, Bresch S, Benzaken S, Marignier R, et al. Only Follow-Up of Memory B Cells Helps Monitor Rituximab Administration to Patients With Neuromyelitis Optica Spectrum Disorders. Neurol Ther (2018) 7:373-83. doi: 10.1007/s40120-018-0101-4

33. Leandro MJ, Cambridge G, Ehrenstein MR, Edwards JC. Reconstitution of Peripheral Blood B Cells After Depletion With Rituximab in Patients With Rheumatoid Arthritis. Arthritis Rheum (2006) 54:613-20. doi: 10.1002/ art. 21617

34. Baris HE, Baris S, Karakoc-Aydiner E, Gokce I, Yildiz N, Cicekkoku D, et al. The Effect of Systemic Corticosteroids on the Innate and Adaptive Immune System in Children With Steroid Responsive Nephrotic Syndrome. Eur J Pediatr (2016) 175:685-93. doi: 10.1007/s00431-016-2694-x

35. Colucci M, Carsetti R, Cascioli S, Serafinelli J, Emma F, Vivarelli M. B Cell Phenotype in Pediatric Idiopathic Nephrotic Syndrome. Pediatr Nephrol (2019) 34:177-81. doi: 10.1007/s00467-018-4095-z

36. Lanzillotta M, Della-Torre E, Milani R, Bozzolo E, Bozzalla-Cassione E, Rovati L, et al. Increase of Circulating Memory B Cells After Glucocorticoid-Induced Remission Identifies Patients at Risk of IgG4-Related Disease Relapse. Arthritis Res Ther (2018) 20:222. doi: 10.1186/s13075-018-1718-5

37. Corcione A, Aloisi F, Serafini B, Capello E, Mancardi GL, Pistoia V, et al. BCell Differentiation in the CNS of Patients With Multiple Sclerosis. Autoimmun Rev (2005) 4:549-54. doi: 10.1016/j.autrev.2005.04.012

38. Jacquot S. CD27/CD70 Interactions Regulate T Dependent B Cell Differentiation. Immunol Res (2000) 21:23-30. doi: 10.1385/IR:21:1:23
39. Funaro A, Spagnoli GC, Ausiello CM, Alessio M, Roggero S, Delia D, et al. Involvement of the Multilineage CD38 Molecule in a Unique Pathway of Cell Activation and Proliferation. J Immunol (1990) 145:2390-6.

40. Zupo S, Rugari E, Dono M, Taborelli G, Malavasi F, Ferrarini M. CD38 Signaling by Agonistic Monoclonal Antibody Prevents Apoptosis of Human Germinal Center B Cells. Eur J Immunol (1994) 24:1218-22. doi: 10.1002/ eji.1830240532

41. Deaglio S, Vaisitti T, Bergui L, Bonello L, Horenstein AL, Tamagnone L, et al. CD38 and CD100 Lead a Network of Surface Receptors Relaying Positive Signals for B-CLL Growth and Survival. Blood (2005) 105:3042-50. doi: 10.1182/blood-2004-10-3873

42. Deaglio S, Capobianco A, Bergui L, Durig J, Morabito F, Duhrsen U, et al. CD38 Is a Signaling Molecule in B-Cell Chronic Lymphocytic Leukemia Cells. Blood (2003) 102:2146-55. doi: 10.1182/blood-2003-03-0989

43. Nutt SL, Hodgkin PD, Tarlinton DM, Corcoran LM. The Generation of Antibody-Secreting Plasma Cells. Nat Rev Immunol (2015) 15:160-71. doi: $10.1038 /$ nri3795

44. Tarlinton D, Good-Jacobson K. Diversity Among Memory B Cells: Origin, Consequences, and Utility. Science (2013) 341:1205-11. doi: 10.1126/ science. 1241146

45. Crotty S, Aubert RD, Glidewell J, Ahmed R. Tracking Human AntigenSpecific Memory B Cells: A Sensitive and Generalized ELISPOT System. J Immunol Methods (2004) 286:111-22. doi: 10.1016/j.jim.2003.12.015

46. Buisman AM, de Rond CG, Ozturk K, Ten Hulscher HI, van Binnendijk RS. Long-Term Presence of Memory B-Cells Specific for Different Vaccine Components. Vaccine (2009) 28:179-86. doi: 10.1016/j.vaccine.2009.09.102

47. Liu YJ, Barthelemy C, de Bouteiller O, Arpin C, Durand I, Banchereau J. Memory B Cells From Human Tonsils Colonize Mucosal Epithelium and Directly Present Antigen to T Cells by Rapid Up-Regulation of B7-1 and B7-2. Immunity (1995) 2:239-48. doi: 10.1016/1074-7613(95)90048-9

48. Jelinek DF, Splawski JB, Lipsky PE. Human Peripheral Blood B Lymphocyte Subpopulations: Functional and Phenotypic Analysis of Surface IgD Positive and Negative Subsets. J Immunol (1986) 136:83-92.

49. Yang M, Rui K, Wang S, Lu L. Regulatory B Cells in Autoimmune Diseases. Cell Mol Immunol (2013) 10:122-32. doi: 10.1038/cmi.2012.60

50. Mauri C, Ehrenstein MR. The 'Short' History of Regulatory B Cells. Trends Immunol (2008) 29:34-40. doi: 10.1016/j.it.2007.10.004

51. Blair PA, Norena LY, Flores-Borja F, Rawlings DJ, Isenberg DA, Ehrenstein MR, et al. CD19(+)CD24(hi)CD38(hi) B Cells Exhibit Regulatory Capacity in Healthy Individuals But Are Functionally Impaired in Systemic Lupus Erythematosus Patients. Immunity (2010) 32:129-40. doi: 10.1016/ j.immuni.2009.11.009

52. Rosenzwajg M, Languille E, Debiec H, Hygino J, Dahan K, Simon T, et al. Band T-Cell Subpopulations in Patients With Severe Idiopathic Membranous Nephropathy May Predict an Early Response to Rituximab. Kidney Int (2017) 92:227-37. doi: 10.1016/j.kint.2017.01.012

53. Muthukumar T, Dadhania D, Ding R, Snopkowski C, Naqvi R, Lee JB, et al. Messenger RNA for FOXP3 in the Urine of Renal-Allograft Recipients. N Engl $J$ Med (2005) 353:2342-51. doi: 10.1056/NEJMoa051907

54. Kap YS, van Driel N, Laman JD, Tak PP, t Hart BA. CD20+ B Cell Depletion Alters T Cell Homing. J Immunol (2014) 192:4242-53. doi: 10.4049/jimmunol.1303125

55. Takahashi S, Wada N, Murakami H, Funaki S, Inagaki T, Harada K, et al. Triggers of Relapse in Steroid-Dependent and Frequently Relapsing Nephrotic Syndrome. Pediatr Nephrol (2007) 22:232-6. doi: 10.1007/ s00467-006-0316-y

56. Du J, Yang H, Guo Y, Ding J. Structure of the Fab Fragment of Therapeutic Antibody Ofatumumab Provides Insights Into the Recognition Mechanism With CD20. Mol Immunol (2009) 46:2419-23. doi: 10.1016/j.molimm.2009.04.009

57. Teeling JL, French RR, Cragg MS, van den Brakel J, Pluyter M, Huang H, et al. Characterization of New Human CD20 Monoclonal Antibodies With Potent Cytolytic Activity Against Non-Hodgkin Lymphomas. Blood (2004) 104:1793-800. doi: 10.1182/blood-2004-01-0039

58. Takeuchi K, Naito S, Kawashima N, Ishigaki N, Sano T, Kamata K, et al. New Anti-Nephrin Antibody Mediated Podocyte Injury Model Using a C57BL/6 Mouse Strain. Nephron (2018) 138:71-87. doi: 10.1159/000479935

59. Brisslert M, Bokarewa M, Larsson P, Wing K, Collins LV, Tarkowski A. Phenotypic and Functional Characterization of Human CD25+ B Cells. Immunology (2006) 117:548-57. doi: 10.1111/j.1365-2567.2006.02331.x 
60. Wherry EJ. T Cell Exhaustion. Nat Immunol (2011) 12:492-9. doi: 10.1038/ ni.2035

61. Wiedeman AE, Muir VS, Rosasco MG, DeBerg HA, Presnell S, Haas B, et al. Autoreactive CD8 + T Cell Exhaustion Distinguishes Subjects With Slow Type 1 Diabetes Progression. J Clin Invest (2020) 130:480-90. doi: 10.1172/ JCI126595

62. Fribourg M, Anderson L, Fischman C, Cantarelli C, Perin L, La Manna G, et al. T-Cell Exhaustion Correlates With Improved Outcomes in Kidney Transplant Recipients. Kidney Int (2019) 96:436-49. doi: 10.1016/ j.kint.2019.01.040

63. Chen L, Jondal M, Yakimchuk K. Regulatory Effects of Dexamethasone on NK and T Cell Immunity. Inflammopharmacology (2018) 26:1331-8. doi: 10.1007/ s10787-017-0418-0

64. Colucci M, Carsetti R, Serafinelli J, Rocca S, Massella L, Gargiulo A, et al. Prolonged Impairment of Immunological Memory After Anti-CD20 Treatment in Pediatric Idiopathic Nephrotic Syndrome. Front Immunol (2019) 10:1653. doi: 10.3389/fimmu.2019.01653
Conflict of Interest: The authors declare that the research was conducted in the absence of any commercial or financial relationships that could be construed as a potential conflict of interest.

Publisher's Note: All claims expressed in this article are solely those of the authors and do not necessarily represent those of their affiliated organizations, or those of the publisher, the editors and the reviewers. Any product that may be evaluated in this article, or claim that may be made by its manufacturer, is not guaranteed or endorsed by the publisher.

Copyright $\odot 2021$ Fribourg, Cioni, Ghiggeri, Cantarelli, Leventhal, Budge, Bin, Riella, Colucci, Vivarelli, Angeletti, Perin and Cravedi. This is an open-access article distributed under the terms of the Creative Commons Attribution License (CC BY). The use, distribution or reproduction in other forums is permitted, provided the original author(s) and the copyright owner(s) are credited and that the original publication in this journal is cited, in accordance with accepted academic practice. No use, distribution or reproduction is permitted which does not comply with these terms. 